
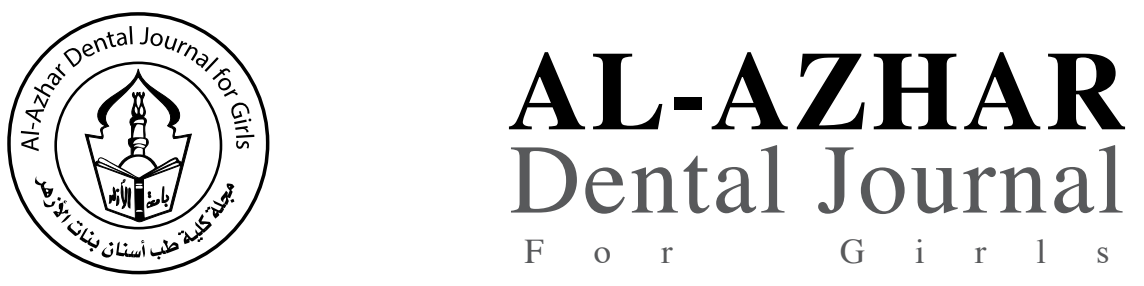

The Official Publication of The Faculty of Dental Medicine For Girls, Al-Azhar University Cairo, Egypt.

ADJ-for Grils, Vol. 4, No. 3, July (2017) — PP. 205:213

\title{
Effect of Incorporation of Hydroxyapatite Nanorods on the Rheological Properties, Micro-shear Bond Strength and Degree of Conversion of Two Dental Adhesives
}

\author{
Nesreen Y. Mohammed ${ }^{(1)}$, Inas T. Motawea ${ }^{(2)}$ and Heba E. Eltayeb $^{(3)}$
}

Codex : 25/1707

dentaljournal.forgirls@yahoo.com

\section{KEYWORDS}

Hydroxyapatite_Adhesive_ rheological properties.

\begin{abstract}
Purpose: The purpose of this study was to evaluate the effect of incorporation of different concentrations of hydroxyapatite nanorods into two adhesives of two commercial adhesive systems in order to evaluate the effect on rheological properties, microshear bond strength and degree of conversion. Materials and Methods: One hundred twenty specimens were used in the present study. The specimens were divided into two main groups $(n=60)$ according to the type of commercial adhesive used AdheSE Bond (I) and Tetric-N Bond Universal (II). Then each group was subdivided into 4 subgroups $(n=15)$ according to the concentration of incorporated HAp nanorods 0 ( control), 0.2, 2, 10wt\%HAp nanorods (A, B, C and D, respectively). Each subgroup was further divided into 3 divisions according to the type of test performed $(n=5)$. For rheological properties measurements, a rheometer was used to measure the viscosity and the viscoelastic behavior of the adhesives. For microshear bond strength testing ( $\mu \mathrm{SBS}$ ), the specimens were tested by using a universal testing machine. The type of failure was determined by using scanning electron microscope. The degree of conversion was measured using Fourier Transform Infrared (FTIR) spectroscopy. The data were analyzed using one-way analysis of variance (ANOVA) and Tukey's post hoc significance difference tests. Differences were considered significant at $\mathrm{p} \leq 0.05$. Two ways analysis of variance ANOVA test was used to study the statistical significance of the interaction between variables (material and HAp nanorods concentrations). Results: The viscosity of experimental adhesives increased gradually with increasing the concentrations of HAp nanorods. In $\mu$ SBS test, the AdheSE containing 0.2 and 2 wt.\% HAp nanorods produced significantly the highest values. Regarding degree of conversion (DC), Tetric-N Bond containing 10wt.\% HAp nanorods produced significantly the highest value of DC. Conclusion: Incorporation of HAp nanorods with low concentration $(0.2 \mathrm{wt} \%)$ in AdheSE Bond had a positive impact on the bond strength. However, HAp nanorods as fillers were not suitable to be incorporated in Tetric-N Bond.
\end{abstract}

1. Paper extracted from thesis titled Effect of Incorporation of Hydroxyapatite Nanorods on the Rheological Properties, Microshear Bond Strength and Degree of Conversion of Two Dental Adhesives.

2. Demonstrator of Dental Biomaterials. Faculty of Dental Medicine, Al-Azhar University (for Girls), Egypt.

3. Assistant Professor and Head of Dental Biomaterials,-Faculty of Dentistry for girls. Al azhar University.

4. Lecturer of Dental Biomaterials, Faculty of Dental Medicine ,Al-Azhar University (for Girls). 


\section{INTRODUCTION}

In dentistry, a true chemical and micromechanical bond of the restorative material to the tooth structure were desired. Recent dental adhesive agents are classified according to the type of tissue conditioning and number of steps for their applications. ${ }^{1} \mathrm{~A}$ strong hydrophobic and low viscosity adhesive resin copolymerizes with the primer penetrating onto the decalcified dentinal surface and simultaneously offers bonding receptors for copolymerization with the restorative resin composite. ${ }^{2}$ The adhesive layer located above the hybrid layer within adhesive zone is considered the weakest spot of an adhesive restoration as microcracks may propagate and undergo hydrolytic degradation. ${ }^{3}$ Thus, there were various efforts to increase the mechanical properties of the adhesive layer through loading fillers, increasing the degree of conversion and improving the monomer system. Among these strategies, fortifying the adhesive with nanoparticles improved its physical and mechanical properties. ${ }^{4}$

Nanotechnology and nanoscience have paved the way by processing a wide variety of nanofillers that improved physical and mechanical properties of adhesives. Moreover, additional biological advantages of the incorporation of nanofillers, as potential antimicrobial and remineralizing activities were proved. Incorporation of fillers into a dental adhesive system can reinforce the adhesive layer resisting the polymerization shrinkage stresses of the overlying composite resin which resulted after light activation, causing gap formation and rupture at the tooth-resin interface. ${ }^{5,6}$ Also, it leads to crack deflection and local plastic deformation around particles. ${ }^{7,8}$

Bonding to dentin is more complex than that to enamel due to its heterogeneous nature with a larger organic content and water. ${ }^{9}$ The quality of the hybrid layer formed at the resin-dentin interface determines the longevity of the adhesive joint. ${ }^{10}$

Synthetic Hydroxyapatite $\left[\mathrm{Ca}_{10}\left(\mathrm{PO}_{4}\right) 6(\mathrm{OH})_{2}\right]$ which is a form of calcium phosphate, is one of the most biocompatible materials which might be beneficial if used as fillers in adhesives. ${ }^{11}$

\section{MATERIALS AND METHODS}

Materials used in this study are shown in table (1):

Table (1) The trade name, composition, manufacturers and Batch number of the materials used in this study.

\begin{tabular}{|c|c|c|c|c|}
\hline Trade name & Type (specification) & Composition & Manufacturer & Batch no. \\
\hline HAp nanorods & $\begin{array}{l}\text { White powder of rod- } \\
\text { shaped nanohydroxy- } \\
\text { apatite particles size } \\
\text { less than } 100 \mathrm{~nm} \text {. }\end{array}$ & $\mathrm{Ca}_{10}\left(\mathrm{PO}_{4}\right)_{6}(\mathrm{OH})_{2}$ & $\begin{array}{l}\mathrm{N} \text { a } \mathrm{n} \text { o }-\mathrm{T} \text { e c h } \\
\text { Company, Egypt, } \\
\text { 6th of October } \\
\text { City, Egypt. }\end{array}$ & - \\
\hline AdheSE System & $\begin{array}{l}2 \text { step self-etch adhe- } \\
\text { sive system } \\
(2-\text { SEA })\end{array}$ & $\begin{array}{l}\text { Self-etch primer: water, dimethacrylate, phos- } \\
\text { phonic acid acrylate, initiators, stabilizers } \\
\text { Bond:, Bis-phenol A di-glycidyl methacrylate. } \\
\text { (Bis-GMA), glycerol di-methacrylate (GDMA), } \\
\text { hydroxyl-ethyl-methacrylate (HEMA), } \\
\text { Initiators and stabilizers. } \\
\text { Fillers: dispersed fumed Silica }(<5 \mathrm{wt} \%) \text {. }\end{array}$ & $\begin{array}{l}\text { Ivoclar, Vivadent, } \\
\text { Schaan, } \\
\text { Liechtenstein. }\end{array}$ & U21135 \\
\hline $\begin{array}{l}\text { Tetric-N Bond } \\
\text { Universal }\end{array}$ & $\begin{array}{l}\text { Single-component } \\
\text { bonding agent in com- } \\
\text { bination with the total- } \\
\text { etch technique. }\end{array}$ & $\begin{array}{l}\text { Phosphoric acid methacrylate (10-MDP), HEMA, } \\
\text { Bis-GMA, methacrylated carboxylic acid polymer } \\
\text { (MCAP), urethanedi-methacrylate (UDMA), etha- } \\
\text { nol, film forming agent, catalysts, and stabilizers. } \\
\text { Filler: }<1 \mathrm{wt} \% \text { silica }\end{array}$ & $\begin{array}{l}\text { Ivoclar Vivadent, } \\
\text { Schaan, } \\
\text { Liechtenstein. }\end{array}$ & $\mathrm{U} 25000$ \\
\hline
\end{tabular}




\begin{tabular}{|c|l|l|l|c|}
\hline Trade name & \multicolumn{1}{|c|}{ Type (specification) } & \multicolumn{1}{|c|}{ Composition } & Manufacturer & Batch no. \\
\hline N-Etch & Phosphoric acid gel. & $\begin{array}{l}\text { Phosphoric acid (37wt\% in water, thickeners and } \\
\text { pigments }\end{array}$ & $\begin{array}{l}\text { Ivoclar, Vivadent, } \\
\text { Schaan, } \\
\text { Liechtenstein. }\end{array}$ & U34429 \\
\hline Tetric N-Ceram & Nano-hybrid composite. & $\begin{array}{l}\text { Matrix: Dimethacrylates (19-20wt.\%). } \\
\text { Fillers: Barium glass, ytterbium trifluoride, mixed } \\
\text { oxide and copolymers } \\
\text { Filler loading }(80-81 \mathrm{wt} \%) .\end{array}$ & $\begin{array}{l}\text { Ivoclar, Vivadent, } \\
\text { Schaan, } \\
\text { Liechtenstein. }\end{array}$ & T47220 \\
\hline
\end{tabular}

Characterization of HAp nanorods and experimental adhesives:

Transmission Electron Microscope (TEM) was used to determine the particle size and shape of HAp powder as well as its distribution within experimental adhesives.

\section{Chemical characterization by Fourier Transform Infrared Spectroscopy (FTIR) spectroscopy:}

It was used to obtain the spectra in the spectral region $4000-400 \mathrm{~cm}^{-1}$ to detect the functional groups of HAp nanorods and detection of these functional groups after its incorporation in both types of adhesives.

\section{Rheological Measurements:}

A rheometer was used to measure viscosities and viscoelastic properties of experimental adhesives by rotational and oscillatory mode of two plates of rheometer, respectively at $37^{\circ} \mathrm{C}$.

\section{Microshear bond strength test procedures:}

For microshear bond strength testing ( $\mu \mathrm{SBS}$ ), dentin slices were prepared and placed in acrylic blocks. Then, they were treated with different adhesives according to the used bonding strategies. Two plastic microtubes were attached to the treated dentin surface and filled with composite resin. The specimens were tested by using a universal testing machine. Representative deboned dentin specimens from all experimental adhesives subgroups (IA, IB, IC, ID,IIA, IIB,IIC and IID) were examined by an environmental scanning electron microscope
(ESEM). The failure mode of the individual specimen was evaluated as one of three types: adhesive (failure at the adhesive interface), cohesive (failure within dentin or composite resin) and mixed (adhesive+cohesive failure of the dentin or composite resin).

\section{The Degree of conversion (DC) measurements:}

FTIR spectroscopy was used to measure the degree of conversion (DC\%). Press-molded $\mathrm{KBr}$ discs were used. A sample of uncured liquid of each experimental adhesive was smeared onto $\mathrm{KBr}$ disc with disposable brush, and then it was loaded into the holder attachment. The uncured sample was removed after the IR spectrum exposure and was covered with celluloid strip and irradiated for 20s with a dental light-curing unit. The percentage of DC was determined by recording the ratio of the height of the absorbance peak of aliphatic $\mathrm{C}=\mathrm{C}$ which appears at peak $1637 \mathrm{~cm}^{-1}$ against the internal standard aromatic $\mathrm{C}=\mathrm{C}$ bond at $1608 \mathrm{~cm}^{-1}$, obtained from both the cured and uncured samples.

The DC\% was calculated by the following equation: ${ }^{12,13}$

$$
\mathrm{DC} \%=1-\frac{\begin{array}{l}
\text { abs }(\text { aliphatic } \mathrm{C}=\mathrm{C}) 1637 / \text { abs } \\
(\operatorname{aromatic} \mathrm{C}=\mathrm{C}) 1608 \text { polymer }
\end{array}}{\begin{array}{c}
\text { abs }(\text { aliphatic } \mathrm{C}=\mathrm{C}) 1637 / \text { abs } \\
(\text { aromatic } \mathrm{C}=\mathrm{C}) 1608 \text { monomer }
\end{array}} \times 100
$$

\section{Statistical analysis}

Data was presented as means and SD values. One-way analysis of variance (ANOVA) test was used to study the effect of different concentrations 
on viscosity, microshear bond strength and degree of conversion. Tukey's post-hoc test was used for pair-wise comparison between the mean values when ANOVA test was significant. The level of significance was set at $\mathrm{p} \leq 0.05$. Unpaired t test was used for comparison between viscosity, degrees of conversion and microshear bond strength in both groups at the same concentration.

\section{RESULTS}

\section{Characterization by Transmission Electron Microscope (TEM):}

The resultant Transmission Electron Microscope (TEM) photomicrographs as shown in figure (1) revealed that the prepared HAp particles had a rod-like shape and size ranging between $20-100 \mathrm{~nm}$ in length and $10-20 \mathrm{~nm}$ in diameter with slight tendency to agglomerate. Also, photomicrograghs of experimental adhesives showed rod-like shape nanoparticles dispersed in adhesive samples with greater size of agglomerations in AdheSE Bond sample rather than that found in Tetric-N Bond.

\section{Chemical characterization by Fourier Transform Infrared (FTIR) spectroscopy of HAp nanorods powder and experimental adhesives:}

FTIR spectrum of the HAp nanorods and experimental adhesives containing HAp nanorods showed the peaks corresponding to the HAp structure as shown in figure $(2,3)$.

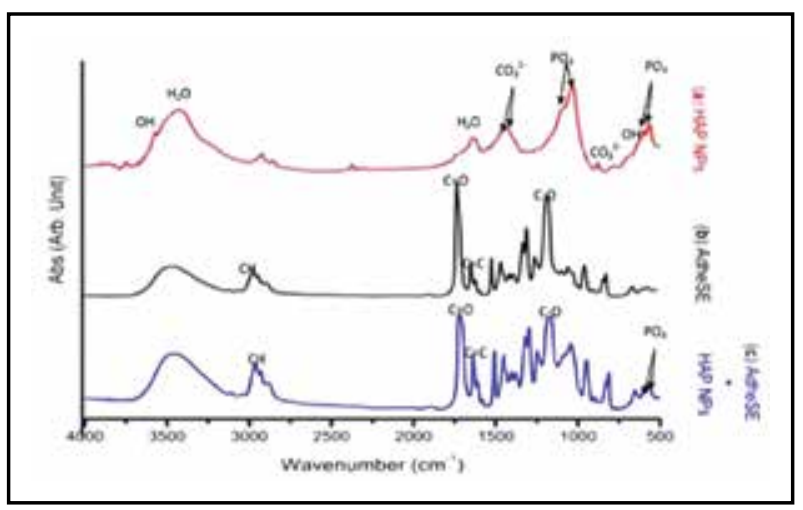

Fig. (2) FTIR spectra of a. HAp nanorods b. AdheSE Bond, and c. AdheSE Bond containing HAp nanorods.

\section{Rheological properties}

There was highly significant difference between AdheSE Bond and Tetric-N Bond at different concentrations. The greatest mean viscosity value was recorded in AdheSE Bond containing $10 \mathrm{wt} \%$ HAp nanorods (ID) $(0.452 \pm 0.099)$, whereas the lowest mean viscosity value was recorded in Tetric-N Bond containing 0.2wt\%HAp nanorods (IIB) $(0.104 \pm 0.003)$ as shown in table (2). This was confirmed by complex viscosities of AdheSE Bond which were much affected by incorporation of HAp nanorods rather than that of Tetric-N Bond Universal except Tetric-N Bond containing 10wt\%HAp nanorods.

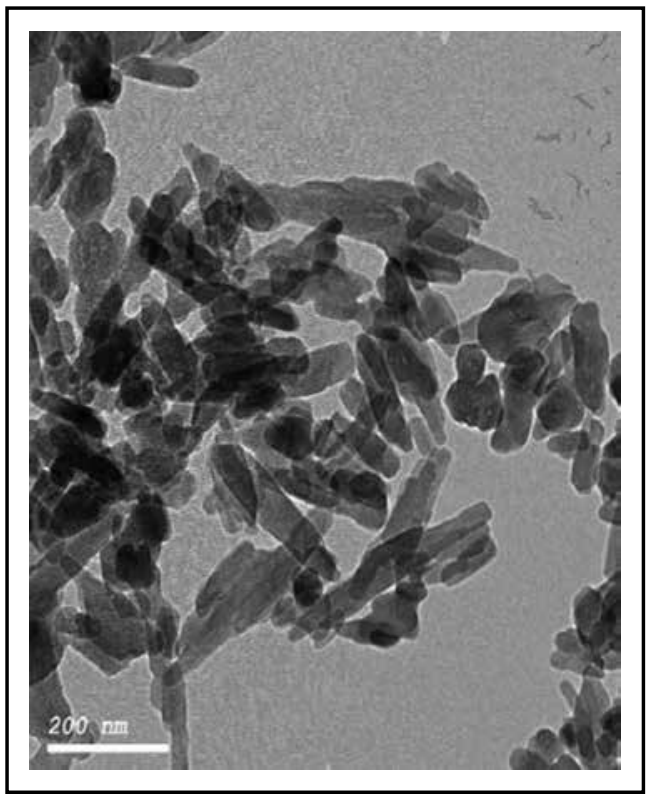

Fig. (1) TEM photomicrogragh of HAp nanorods particles used in this study.

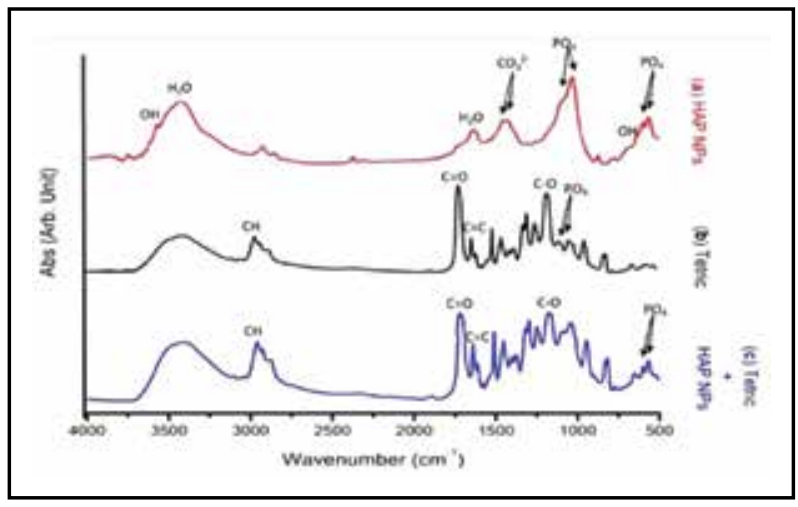

Fig. (3) FTIR spectra of a. HAp nanorods, b. Tetric-N Bond, and c. Tetric-N Bond containing HAp nanorods. 
Table (2): Comparison between viscosity measurements (Pa.s) of AdheSE Bond and Tetric-N Bond (I and II) at the same concentration.

\begin{tabular}{|c|c|c|c|c|c|c|c|}
\hline & & & & & & t value & P value \\
\hline \multirow{2}{*}{ 0wt.\%(A) } & Mean & \multirow{2}{*}{ IA } & 0.271 & \multirow{2}{*}{ IIA } & 0.155 & \multirow{2}{*}{11.5} & \multirow{2}{*}{$<0.0001 *$} \\
\hline & SD & & 0.026 & & 0.006 & & \\
\hline \multirow{2}{*}{$0.2 \mathrm{wt} . \%$ (B) } & Mean & \multirow{2}{*}{ IB } & 0.304 & \multirow{2}{*}{ IIB } & 0.104 & \multirow{2}{*}{9.11} & \multirow{2}{*}{$<0.0001 *$} \\
\hline & SD & & 0.058 & & 0.003 & & \\
\hline \multirow{2}{*}{$2 \mathrm{wt} . \%(\mathrm{C})$} & Mean & \multirow{2}{*}{ IC } & 0.375 & \multirow{2}{*}{ IIC } & 0.122 & \multirow{2}{*}{6.94} & \multirow{2}{*}{$<0.0001$} \\
\hline & $\mathrm{SD}$ & & 0.094 & & 0.021 & & \\
\hline \multirow{2}{*}{$10 \mathrm{wt} . \%$ (D) } & Mean & \multirow{2}{*}{ ID } & 0.452 & \multirow{2}{*}{ IID } & 0.376 & \multirow{2}{*}{0.7351} & \multirow{2}{*}{$0.4764^{\mathrm{ns}}$} \\
\hline & $\mathrm{SD}$ & & 0.099 & & 0.255 & & \\
\hline
\end{tabular}

*Highly significant.

ns=non-significant.

Storage shear moduli $\left(\mathrm{G}^{\prime}\right)$ and loss shear moduli $\left(\mathrm{G}^{\prime \prime}\right)$ versus angular frequency at (1-100 $\left.\mathrm{rad} / \mathrm{s}\right)$ for AdheSE Bond were obtained. Both $G^{\prime}$ and $\mathrm{G}$ "increased with increasing frequency. However, almost no difference in values of $G^{\prime}$ and $G^{\prime \prime}$ among the different concentrations of AdheSE Bond was shown. Moreover, loss shear moduli (G") dominated over storage shear moduli G' among all different concentrations.

Storage $\left(G^{\prime}\right)$ and loss $\left(G^{\prime \prime}\right)$ shear moduli versus angular frequency for Tetric-N Bond were obtained. Both $\mathrm{G}^{\prime}$ and $\mathrm{G}^{\prime \prime}$ increased with increasing frequency but showed almost no differences in values of $\mathrm{G}^{\prime}$ and $\mathrm{G}^{\prime \prime}$ among Tetric-N Bond containing 0, 0.2 and 2 wt.\%HAp nanorods, whereas, Tetric-N Bond containing $10 \mathrm{wt} . \%$ revealed increase in storage and loss shear moduli values at applied angular frequencies. Moreover, $\mathrm{G}^{\prime}$ and $\mathrm{G}^{\prime \prime}$ moduli showed almost parallel straight lines throughout the entire frequency range showing slight slope only. In addition to that $\mathrm{G}^{\prime}$ were obviously higher than $\mathrm{G}^{\prime \prime}$ among all values of applied angular frequencies in Tetric-N Bond containing different concentrations.

\section{Microshear bond strength ( $\mu S B S)$ :}

There was a highly statistically significant difference between AdheSE Bond and Tetric-N Bond at different concentrations. AdheSE Bond containing $0.2 \mathrm{wt} \% \mathrm{HApnanorods} \mathrm{showed} \mathrm{the} \mathrm{highest} \mathrm{bond}$ strength (25.57MPa \pm 10.33$)$. Whereas AdheSE Bond containing 10wt\%HAp nanorods showed the lowest bond strength $(6.22 \mathrm{MPa} \pm 2.35)$ as shown in table (3). Evaluation of failure modes by ESEM showed that high values of $\mu \mathrm{SBS}$ tended to exhibit cohesive or mixed failure while low values tended to show adhesive failure.

Table (3): Comparison of bond strength ( $\mu \mathrm{SBS}$ ) values (MPa) between AdheSE and Tetric N-Bond (I and II) at at the same concentration of HAp nanorods.

\begin{tabular}{|c|c|c|c|c|c|}
\hline & & (I)AdheSE & (II) Tetric N Bond & t value & P value \\
\hline \multirow{2}{*}{ A- 0 wt $\%$} & Mean & 6.86 & 12.9 & \multirow{2}{*}{2.6364} & \multirow{2}{*}{$0.0299^{\mathrm{s}}$} \\
\hline & SD & 3.91 & 3.31 & & \\
\hline \multirow{2}{*}{ B- $0.2 \mathrm{wt} \%$} & Mean & 25.57 & 17.36 & \multirow{2}{*}{1.5406} & \multirow{2}{*}{$0.1620^{\mathrm{ns}}$} \\
\hline & SD & 10.33 & 5.94 & & \\
\hline \multirow{2}{*}{$\mathrm{C}-2 \mathrm{wt} \%$} & Mean & 24.54 & 13.77 & \multirow{2}{*}{3.2879} & \multirow{2}{*}{$0.0111^{\mathrm{s}}$} \\
\hline & SD & 4.55 & 5.74 & & \\
\hline \multirow{2}{*}{ D- $10 w t \%$} & Mean & 6.22 & 10.24 & \multirow{2}{*}{2.839} & \multirow{2}{*}{$0.0111^{\mathrm{s}}$} \\
\hline & SD & 2.35 & 3.84 & & \\
\hline
\end{tabular}

$s=$ significant at $p<0.05 . \quad n s=$ non-significant. 


\section{Degree of conversion (DC \%)}

There was a statistically significant difference between AdheSE Bond and Tetric-N bond at different concentrations. Tetric-N Bond containing 10wt\%HAp nanorods showed the highest degree of conversion (51.95 \pm 8.20$)$. Whereas AdheSE Bond containing 10wt\%HAp nanorods recorded the least degree of conversion (20.42 \pm 4.96$)$ as shown in table (4).

Table (4): Comparison of degree of conversion (DC \%) between AdheSE Bond and Tetric- $N$ Bond groups at the same concentration.

\begin{tabular}{|c|c|c|c|c|c|}
\hline & & I AdheSE & II Tetric N Bond & t value & P value \\
\hline A- $0 \mathrm{wt} \%$ & $\begin{array}{l}\text { Mean } \\
\text { SD }\end{array}$ & $\begin{array}{c}27.45 \\
7.88\end{array}$ & $\begin{array}{l}34.312 \\
11.282\end{array}$ & 0.627 & $0.565^{\mathrm{ns}}$ \\
\hline B- $0.2 \mathrm{wt} \%$ & $\begin{array}{l}\text { Mean } \\
\text { SD }\end{array}$ & $\begin{array}{c}24.44 \\
7.01\end{array}$ & $\begin{array}{l}37.55 \\
16.82\end{array}$ & 1.412 & $0.231^{\mathrm{ns}}$ \\
\hline C- $2 w t \%$ & $\begin{array}{c}\text { Mean } \\
\text { SD }\end{array}$ & $\begin{array}{c}21.81 \\
7.29 \\
\end{array}$ & $\begin{array}{c}44.24 \\
5.85 \\
\end{array}$ & 10.481 & $<0.000^{*}$ \\
\hline D- $10 w t \%$ & $\begin{array}{l}\text { Mean } \\
\text { SD }\end{array}$ & $\begin{array}{c}20.42 \\
4.96\end{array}$ & $\begin{array}{c}51.95 \\
8.20\end{array}$ & 5.546 & $\mathbf{0 . 0 0 5}^{\mathrm{s}}$ \\
\hline
\end{tabular}

* Highly significant.

$s=$ significant at $P<0.05 . \quad n s=$ non-significant.

\section{DISCUSSION}

Nowadays, the dental field approves the use of self-etching adhesives but still with great concern regarding their bonding strength. ${ }^{14}$

Incorporation of nano-filler particles into resin matrix can improve the physical and mechanical properties of dental adhesives. ${ }^{15}$

\section{Rheological properties:}

AdheSE Bond with different concentrations showed higher statistically significant mean values of viscosities compared to those of Tetric-N Bond $(\mathrm{p}=0.0001)$. This could be explained by the fact that AdheSE Bond contains originally fillers $(<5 \%$ $\mu$ silica) more than Tetric-N Bond ( $<1 \% \mu$ silica). In addition to the nature of Bis-GMA monomer which is a viscous component due to the presence of hydrogen bonding, caused by hydroxyl groups in its molecule, as well as presence of aromatic rings. ${ }^{16}$ Tetric-N Bond contains UDMA monomer which acts as a diluent. ${ }^{17}$ Moreover, this evidence might reflect the difference in blends of monomers between both adhesives used in this study.
Experimental adhesives of AdheSE Bond showed shear thinning behavior of flow. This strong particle-particle interaction of fillers is one major factor that led to an increase in viscosity among different concentrations of AdheSE Bond (I). These results were in accordance with results obtained by a study who investigated flow properties of filled Bis-GMA. ${ }^{18}$ Also, this was in agreement with the results obtained that pit and fissure sealant exhibited non-Newtonian shear thinning behavior. On the contrary, Tetric-N Bond with different concentrations showed Newtonian behavior except that contained 10wt\% HAp nanorods showed shear thinning behavior. It was observed that loss shear modulus (viscous portion;G") dominated storage shear modulus (elastic portion;G') at almost applied frequencies with nearly no differences in their values among the different tested concentrations. This might be attributed to the fact that even highviscosity materials with entangled molecule chains but without any chemical or physical network were showing this behavior. ${ }^{19}$ This was in agreement with a study which showed that $\mathrm{G}^{\prime}$ and $\mathrm{G}^{\prime}$ increased 
by increasing the amount of Laponite (nano-sized clay). The loss modulus $\mathrm{G}^{/ /}$was larger than the storage modulus $\mathrm{G}^{\prime}$ indicating that the viscous behavior was dominated and the sample displays liquid-like behavior. $^{20}$

In case of Tetric-N Bond with different concentrations of HAp nanorods, that storage shear modulus (elastic portion; G') exceeded loss shear modulus (viscous portion; $G$ ") for all frequencies with nearly no change in values of $\left(G^{\prime}\right)$ and $\left(G^{\prime \prime}\right)$ among different concentrations $(0,0.2,2 \mathrm{wt} \% \mathrm{HAp}$ nanorods) except that contained 10wt\% HAp nanorods. This could be explained that even with low-viscosity flow behavior, gel structure or even weak gel structure might be obtained. Also, this could be explained that Tetric-N Bond showed more stable dispersion. Therefore, elastic behavior dominated the viscous one. According to Tetric-N Bond containing $10 \mathrm{wt} \% \mathrm{HAp}$ nanorods (IID), G' and G' became almost parallel straight lines throughout the entire frequency range showing a slight slope only. In addition, there was an increase in values of G' and G' of Tetric-N Bond containing10wt\%HAp nanorods. This might be due to HAp nanorods that produced chemical interaction in such adhesive. Chemical interaction might occur at this concentration between10MDP and 10wt $\%$ HAp nonorods..$^{21}$ However, no works reported in the literature about the dynamic oscillatory measurements for dental adhesives.

\section{Microshear bond strength test ( $\mu S B S)$}

The microshear bond test has now been accepted as a reliable and facile method of measuring the bond strength of dental adhesives to the tooth structure. The method was introduced to overcome the drawbacks of the macroshear test that was inhomogeneous distribution of stress in the area over which the load is applied. In the present study, the incorporation of 0.2 and $2 \mathrm{wt} \% \mathrm{HAp}$ nanorods, the greater mean values of $\mu$ SBS was found in AdheSE bonding $(25.57 \pm 10.33$ and $24.54 \pm 4.55 \mathrm{MPa})$ rather than those of Tetric-N Bond $(17.36 \pm 5.94$ and $13.77 \pm 5.74 \mathrm{MPa})$ ,respectively. This might be due to the $\mathrm{pH}$ of AdheSE primer $\sim 1.6$. This acidity is buffered by HAp incorporated into the AdheSE Bond when applied on dentin. This buffering action suppressed negative effect of acidity on co-initiator system. Hence, this enhanced the degree of conversion on the tooth structure and increased the bond strength. This was in agreement with a study that showed increasing the degree of conversion following the addition of 3-4wt.\%HAp fillers to experimental self-etch adhesive. However, incorporation of HAp nanorods into Tetric-N Bond caused neutralization of 10MDP diminishing its micromechanical and bonding efficacy to dentin. ${ }^{22,23}$

However, at 10wt \% HAp nanorods, AdheSE Bond showed lower mean value of $\mu \mathrm{SBS}$ than that of Tetric-N Bond. This could be explained that at this concentration, amount of filler increased markedly in AdheSE Bond (5\%silica+10wt.\%HApnanorods) which caused further agglomeration rather than that of Tetric-N Bond (1wt.\%silica+10wt.\% HAp nanorods), so there was no further enhancement at these concentrations. Moreover, higher amounts of filler especially at the nanoscale increased the viscosity of the polymer, resulting in difficult diffusion into demineralized dentin and lower bond strength. These results were supported by ESEM photomicrograghs. They showed that AdheSE Bond and Tetric-N Bond containing 10wt\% HAp nanorods, adhesive and mixed failure respectively (exposing dentin with improper infiltrated resin tags).

In the present study, etch and rinse strategy (phosphoric acid etching) with Tetric-N Bond Universal was used. It did not affect the bond strength of its experimental adhesives containing HAp nanorods. This was attributed to the greater portion of HAp which removed from dentin by phosphoric acid etching following etch and rinse strategy. This left a very limited amount of natural HAp at the dentin surface for chemical interaction with 10MDP of Tetric-N Bond. At the same time 10-MDP was buffered by adding the HAp nanorods. This was in agreement with a study showed that the addition of HAp nanorods to Universal adhesive with etch and rinse strategy did not affect its bond strength. ${ }^{22}$ 


\section{Degree of conversion $(D C)$}

Assessing the degree of conversion (DC) was carried out using Fourier transform infrared spectroscopy (FTIR). The DC of adhesives is one of the determining factors for a durable dentin bonding. A suboptimal DC might be responsible for the reduced interfacial strength and inherent interface instability. ${ }^{24}$

In the present study, DC of Tetric-N Bond was higher than those of AdheSE Bond at the different concentrations $(0.2,2,10 \mathrm{wt} \% \mathrm{HAp}$ nanorods) of both adhesives. This might be attributed to the functional monomer of Tetric-N Bond (10MDP) that was present in the same adhesive bottle system (that was designed under the concept; one-step self-etch adhesives) led to direct contact between HAp nanorods and the acidic monomer causing neutralization of acidity of Tetric-N Bond increasing DC. This effect increased by increasing HAp nanorods content. ${ }^{25}$ Meanwhile the AdheSE Bond devoid from such functional monomer in two-step self-etch adhesive system where functional monomer was found in the primer. The present results were in agreement with a previous studies ${ }^{26,27}$ which concluded that the DCs of experimental self-etching adhesives was improved through their interaction of MDP with HAp.

\section{CONCLUSION}

Under the limitation of this study, it was found that:

1. The viscosity of experimental adhesives increased gradually with increasing the concentrations of HAp nanorods.

2. Incorporation of HAp nanorods with low concentration $(0.2 \mathrm{wt} \%)$ in AdheSE Bond showed the highest bond strength.

3. Incorporation of HAp nanorods into Tetric-N Bond didn't affect significantly bond strength.

4. Degree of conversion of Tetric-N Bond with different concentrations of HAp nanorods was significantly increased with increasing the concentration of HAp nanorods.

\section{RECOMMENDATION}

It is recommended to incorporate $0.2 \mathrm{wt} \% \mathrm{HAp}$ nanorods to AdheSE Bond to improve its low bond strength of AdheSE system. However, HAp nanorods as fillers are not suitable to be incorporated in Tetric-N Bond. Further investigations regarding bond durability of experimental adhesive of AdheSE Bond containing $0.2 \mathrm{wt} \% \mathrm{HAp}$ nanorods should be performed.

\section{REFERENCES}

1. Sarr M, Kane AW, Vreven J, Mina A, Van Landuyt KL, Peumans M, Lambrechts P, Van Meerbeek B, Munck JD. Microtensile bond strength and interfacial characterization of 11 contemporary adhesives bonded to Bur-cut dentin. Oper Dent 2010;35:94-04.

2. Van Landuyt KL, Snauwaert J, De Munck J, Peumans M, Yoshida Y, Poitevin A, Coutinho E, Suzuki K, Lambrechts P, Van Meerbeek B. Systematic review of the chemical composition of contemporary dental adhesives. Biomater 2007;28;3757-85.

3. Hashimoto M, Ohno H, Sano H, Kaga M, Oguchi H. Degradation patterns of different adhesives and bonding procedures. J. Biomed. Mater. Res. Part B Appl. Biomater 2003;66:324-30.

4. Conde $\mathrm{MC}$, Zanchi CH, Rodrigues-Junior SA, Carreno NL, Ogliari FA, Piva E. Nanofiller loading level: influence on selected properties of an adhesive resin. J Dent 2009;37:331-35.

5. Kim JS, Cho BH, Lee LB, Um CM, Lim BS, Oh MH, Chang $\mathrm{CG}$, Son HH. Effect of the hydrophilic nanofiller loading on the mechanical properties and the micro-tensile bond strength of an ethanol-based one-bottle dentin adhesive. J Biomed Mater Res Part B: Appl Biomat 2005:72:284-91.

6. Suryakumari N B, Reddy LR, Surender R. In vitro evaluation of influence of salivary contamination on the dentin bond strength of one-bottle adhesive systems. Contemp Clin Dent 2011;2:160-64.

7. Crosby AJ, Lee JY. Polymer Nanocomposites: The nano effect on mechanical properties. Polymer Rev 2007;47:217-29.

8. Sun J, Forster AM, Johnson PM, Eideiman N, Quinn G, Sohumacher G, Zhang X, Wu Wl. Improving performance of dental resins by adding titanium dioxide nanoparticles. Dent Mater 2011:27:972-82. 
9. Hashimoto M, Nagano F, Endo K, Ohno H. A review: Biodegradation of resin-dentin bonds. Jpn Dent Sci Rev. 2011;47:5-12.

10. Tjäderhane L, Nascimento FD, Breschi L, Mazzoni A, Tersariol IL, Geraldeli S. PashleyDH. Optimizing dentin bond durability: control of collagen degradation by matrix metalloproteinases and cysteine cathepsins. Dent Mater 2013;29: 116-35.

11. Paz A, Guadarrama D, López M, González JE, Brizuela N, Aragón J. A comparative study of hydroxyapatite nanoparticles synthesized by different routes. Quim. Nova 2012; 35: 1724-7.

12. Gaglianone LA, Lima AF, Gonçalves LS, Cavalcanti AN, Aguiar FHB, Marchi GM. Mechanical properties and degree of conversion of etch-and-rinse and self-etch adhesive systems cured by a quartz tungsten halogen lamp and a light-emitting diode. J Mech Behav Biom Mater 2012;12:139-43.

13. Durner J, Obermaier J, Draenert M, Ilie N. Correlation of the degree of conversion with the amount of elutable substances in nano-hybrid dental composites. Dent Mater 2012;28:1146-53.

14. De Munck J, Van Landyt K, Peumans M, Poitevin A, Lambrechts P, Braem M, et al. A critical review of the durability of adhesion to tooth tissue: methods and results. J Dent Res 2005;84:118-32.

15. Akhavan A, Sodagar A, Motjahedzadeh F, Sodagar K. Investigating the effect of incorporating nanosilver/ nanohydroxyapatite particles on the shear bond strength of orthodontic adhesives. Acta Odontol Scand 2013; 71:1038-42.

16. Park ES, Kim CK, Bae JH, Cho BH. The effect of the strength and wetting characteristics of Bis-GMA/ TEGDMA-based adhesives on the bond strength to dentin. JKACD 2011;36:139-48.

17. Van Landuyt KL, Snauwaert J, De Munck J, Peumans M, Yoshida Y, Poitevin A, Coutinho E, Suzuki K, Lambrechts P, Van Meerbeek B. Systematic review of the chemical composition of contemporary dental adhesives. Biomater 2007;28;3757-85.

18. Papakonstantinou AE, Eliades T, Cellesi F, Watts DC, Silikas N. evaluation of UDMA's potential as a substitute for Bis-GMA in orthodontic adhesives. J Dent Mat 2013;29:898-905.

19. Mezger TG. The rheology Handbook for users of rotational and oscillatory rheometers. 2nd ed. 2006:18,34,125,234.

20. Shen M, Sun LLY, Xu J, Guo X, Prudhomme RK. Rheology and adhesion of Poly(acrylic acid)/Laponite Nanocomposite Hydrogels as Biocompatible Adhesives. Langmuir 2014; 30:1636-42.

21. Zhang Y, Wang Y. Improved degree of conversion of model self-etching adhesives through their interaction with dentin. J Dent 2013;40:57-63.

22. Lezaja M, Jokic BM, Veljovic DN, Miletic V. Shear bond strength to dentin of dental adhesives containing hydroxyapatite nanofillers. J Adhes Sci Tech 2016;30:267889.

23. Elkassas DW, Haridy MF. Degree of conversion, flexural strength and bond strength durabilityof a contemporary universal dentin adhesive fortified with silver and hydroxyapatite nanoparticles. EDJ 2015;61:1-12.

24. Moraes LGP, Rocha RSF, Menegazzo LM, de Araujo EB, Yukimitu K, Moraes JCS. Infrared Spectroscopy: A tool for determination of the degree of conversion in dental composite. J Appl Oral Sci 2008;16:145-9.

25. Melo MAS, Cheng L, Zhang K, Weir MD, Rodrigues LKA, $\mathrm{Xu}$ HHK. Novel dental adhesives containing nanoparticles of silver and amorphous calcium phosphate. Dent Mater 2013;29:199-210.

26. Zhang Y, Wang Y. The effect of hydroxyapatite presence on the degree of conversion and polymerization rate in a model selfetching adhesive. Dent Mater 2012;28:23744.

27. Palin WK, Fleming GJP, Trevor BFG, Marquis PM, Randall RC. Monomer conversion versus flexure strength of novel dental composite. J Dent 2003;31:341-51. 